\title{
Ficção televisiva brasileira e fãs on-line: mapeamentos e investigações
}

\begin{abstract}
Lucas Martins Néia
Roteirista. Mestrando em Ciências da Comunicação pela Escola de Comunicações e Artes da Universidade de São Paulo. Pesquisador do Centro de Estudos de Telenovela (CETVN/ ECA-USP) e do Observatório Ibero-americano da Ficção Televisiva (Obitel). Bolsista CNPq. E-mail: lucas_martins_neia@hotmail.com
\end{abstract}

Resumo: O texto apresenta uma síntese da obra Por uma teoria de fãs da ficção televisiva brasileira', resultado de dez pesquisas colaborativas desenvolvidas entre 2014 e 2015 pelas equipes de investigadores da rede Obitel Brasil. Enfocam-se, primeiramente, as diferentes abordagens promovidas pelos pesquisadores frente à questão do fã da ficção televisiva brasileira como sujeito ativo na produção cultural, inserido no contexto das tecnologias digitais. Ressalta-se, por fim, a importância destes estudos no atual panorama da Comunicação.

Palavras-chave: fãs; ficção televisiva; cultura participativa; engajamento; cultura fandom.
Abstract: This paper presents a summary of the work "Por uma teoria de fãs da ficção televisiva brasileira", result of ten collaborative investigations developed between 2014 and 2015 by a team of researchers from the group Obitel Brazil. It focuses on the different approaches to the issue of television fiction fan as an active subject in cultural production, placed in the context of digital technologies. Finally, the paper highlights the importance of these studies in the current communication scenario.

Keywords: fandom culture; participatory culture; engagement; fans; television fiction.

Em Ficção televisiva no Brasil: temas e perspectivas, gênese da Coleção Teledramaturgia e primeira publicação da Rede Brasileira de Pesquisadores de Ficção Televisa Obitel Brasil ${ }^{2}$, Lopes et al. apontavam para a fragilidade dos conceitos e propostas metodológicas que, à época, procuravam dar conta de uma realidade empírica multimidiática ${ }^{3}$. Passados nove anos, é possível constatar que a rede Obitel Brasil se consolidou justamente pelo desenvolvimento de pesquisas colaborativas que localizam as ficções televisivas em meio às novas dinâmicas dos sistemas comunicacionais - naquilo que Lopes classifica como ecossistema midiático ${ }^{4}$.

1. LOPES, Maria Immacolata Vassallo de (org.). Por uma teoria de fãs da ficção televisiva brasileira. Coleção Teledramaturgia, v. 4. Porto Alegre: Sulina, 2015. O livro foi publicado com o apoio do Globo Universidade. Versão digital disponível para download no endereço: <http://obitelbrasil.blogspot.com.br>.

2. Braço nacional do Observatório lbero-americano da Ficção Televisiva (Obitel). Criado em 2005 na cidade de Bogotá, o Obitel é uma rede internacional formada por grupos de pesquisa de doze países - Argentina, Brasil, Chile, Colômbia, Espanha, Equador, Estados Unidos (de língua hispânica), México, Peru, Portugal, Uruguai e Venezuela; todos os grupos adotam um protocolo metodológico unificado para, por meio do monitoramento anual e da análise comparada - quantitativa e qualitativa - dos vários formatos de ficção televisiva, traçarem o diagnóstico e as perspectivas do gênero no espaço ibero-americano. O Obitel Brasil, por sua vez, se constituiu em 2007 com o objetivo de reunir pesquisadores especializados em ficção televisiva, provenientes de universidades e centros de diferentes regiões do país.

3. LOPES, Maria Immacolata Vassallo de. Transmediação, plataformas múltiplas, colaboratividade e criatividade na ficção televisiva brasileira. In: Idem (org.). Ficção televisiva no Brasil: temas e perspectivas. Coleção Teledramaturgia, v. 1. São Paulo: Globo, 2009, pp. 395-396. Teledramaturgia, v. 4. Porto Alegre: Sulina, 2015. O livro foi publicado com o apoio do Globo Universidade. Versão digital disponível para download no endereço: <http://obitelbrasil.blogspot.com.br>.

4. Idem, p. 398. 
5. Idem (org.). Ficção televisiva transmidiática no Brasil: plataformas, convergência, comunidades virtuais. Coleção Teledramaturgia, v. 2. Porto Alegre: Sulina, 2011.

6. Idem (org.). Estratégias de transmidiação na ficção televisiva brasileira. Coleção Teledramaturgia, v. 3. Porto Alegre: Sulina, 2013.

7. LOPES, Maria Immacolata Vassallo de; MUNGIOLI, Maria Cristina Palma. A autoconstrução do fã: performances e estratégias de fãs de telenovela na internet. In: LOPES, Maria Immacolata Vassallo de (org.). Por uma teoria de fãs da ficção televisiva brasileira. Coleção Teledramaturgia, v. 4. Porto Alegre: Sulina, 2015, p. 17.

8. Professora da Escola de Comunicações e Artes da Universidade de São Paulo e coordenadora do Centro de Estudos de Telenovela (CETVN/ ECA-USP), do Obitel e do Obitel Brasil.
A partir do segundo volume da coleção, intitulado Ficção televisiva transmidiática no Brasil: plataformas, convergência, comunidades virtuais ${ }^{5}$, os grupos de pesquisa passaram exclusivamente a investigar a produção, a circulação e o consumo de ficções televisivas em seus processos de transmidiação - no contexto da referida publicação, a abordagem soava inédita no país. No terceiro volume, Estratégias de transmidiação na ficção televisiva brasileira ${ }^{6}$, as investigações prosseguiram, apontando para uma lógica cada vez mais latente de retroalimentação de conteúdos entre produtores e receptores de ficção televisiva. Acerca deste processo, pontuam Lopes, Mungioli et al.:

O engajamento [...] parece ter ocorrido, em etapas iniciais, apenas em função de curtir, seguir e ser seguido, progredindo para a etapa seguinte, de criação de conteúdos - também referida como Conteúdo Gerado pelo Usuário (CGU). A partir dessa perspectiva, é possível afirmar que talvez nunca tenhamos observado, como no momento atual, tão intenso fluxo de conteúdos que atravessam diferentes mídias e que são reinventados a partir de cada uma delas ${ }^{7}$.

A perspectiva, ao que parece, induziu a rede a atentar mais especificamente para as práticas e motivações desses usuários — ou melhor, "espectadores ativos". No biênio 2014/2015, novamente sob a liderança de Maria Immacolata Vassallo de Lopes ${ }^{8}$, cerca de noventa pesquisadores (de seniores, seus respectivos doutorandos e mestrandos, a bolsistas de iniciação científica), alocados em dez grupos de pesquisa provenientes de universidades dos estados da Bahia, Minas Gerais, Pernambuco, Rio de Janeiro, Rio Grande do Sul e São Paulo, voltaram-se a questões relativas a fãs, cultura de participação, engajamento etc.

Da empreitada, nasceu o livro Por uma teoria de fãs da ficção televisiva brasileira, quarto volume da Coleção Teledramaturgia. Divididos em três partes - (I) Elementos para uma teoria de fãs no Brasil; (II) Cultura de fãs e ficção televisiva; e (III) Cultura participativa e ficção televisiva —, seus capítulos se construíram a partir de diferentes aspectos teórico-metodológicos, sempre partindo da investigação e do monitoramento de plataformas diversas - de revistas a sites, blogs e redes sociais como Facebook, Twitter e Instagram. A publicação, dessa forma, busca descortinar o impacto da cultura participativa — ou, mais especificamente, das possibilidades de participação dos fãs propiciadas pelas mídias interativas — nos processos de produção, circulação e recepção da ficção televisiva brasileira, em especial a telenovela.

O capítulo "A autoconstrução do fã: performances e estratégias de fãs de telenovela na internet", orientado por Maria Immacolata Vassallo de Lopes e Maria Cristina Palma Mungioli - coordenadoras da equipe Obitel Brasil/ USP —, inicia a primeira parte do livro. Partindo de aportes teóricos relacionados à construção do self e a gradações de engajamento dos fãs, exploram-se cinco casos empíricos, nos quais se discutem os processos de autoconstrução de fãs curadores - moderadores de comunidades, organizadores de listas de discussão e autores de blogs ou fanpages acerca de ficção televisiva, principalmente telenovela. Constata-se, por meio das histórias de vida e das atividades em blogs e sites, que a subjetividade e as performances desses fãs 
se constroem intrinsecamente ligadas às narrativas de ficção da televisão por eles acompanhadas.

O segundo capítulo, coordenado por Maria Aparecida Baccega e Marcia Perencin Tondato, da equipe Obitel Brasil/ESPM, realiza um interessante apanhado diacrônico referente à memória midiática, contrapondo o fã tão ativo em blogs e fanpages de telenovelas aos que integravam os antigos fã-clubes e enviavam cartas para as "colunas dos leitores" de revistas como Intervalo, Amiga e Contigo, espaços que constituíam mediadores importantes da relação ficcional-simbólico/ cotidiano-imaginário ${ }^{9}$. Intitulado "Fãs de telenovelas: construindo memórias das mídias tradicionais às digitais”, o texto aponta que essas antigas revistas já criavam e mantinham um ambiente de estímulo à participação e interatividade - o que, no meio digital, devido à instantaneidade da repercussão de opiniões e comentários, potencializa a característica da telenovela como uma "obra em aberto", causando, por exemplo, a antecipação de focus groups para discussão dos rumos da trama.

Alguns fãs preferem se apropriar de fato nos universos de suas tramas favoritas, investindo em criações literárias que se baseiem naquele mundo ficcional, somente em alguns personagens ou até mesmo em artistas preexistentes. Essas criações foram objeto de análise do capítulo "Entre novelas e novelos: um estudo das fanfictions de telenovelas brasileiras (2010-2013)", texto do Obitel Brasil/UFBA que encerra a primeira parte do livro. A pesquisa, orientada por Maria Carmem Jacob de Souza, observa duas vertentes nas performances das autoras de fanfictions de telenovela: enquanto algumas são motivadas somente pela vontade de manifestar nostalgias ou frustrações relacionadas aos conteúdos das ficções televisivas originais, partilhando dessas emoções com a comunidade de leitores, outras canalizam o prazer da escrita e suas pretensões autorais no material, ampliando o universo ficcional da telenovela de base. Em ambos os casos, há uma importância clara dos repositórios e da diversidade de usos das plataformas: no primeiro, prioriza-se a vida social e afetiva de pequenos grupos consumidores de telenovelas; no segundo, cultiva-se e amplia-se o público leitor destas fanfictions, distribuídas articuladamente por sites, blogs e fanpages.

A segunda parte do livro se concentra na mobilização de fandoms - grupos de pessoas que se unem por um interesse comum, tecendo relações de camaradagem e solidariedade uns com os outros ${ }^{10}$ - em torno de teleficções específicas, exibidas entre 2010 e 2014. O primeiro capítulo dessa unidade, resultado das investigações do Obitel Brasil/UFSCar - coordenado por João Massarolo e Dario Mesquita —, lança um olhar ao contexto da emergente produção seriada nacional. "Redes discursivas de fãs da série Sessão de Terapia" delineia uma cartografia de discursos e práticas on-line dos fãs da temporada 2014 (a última) da ficção televisiva em questão, exibida pelo canal pago GNT. O estudo leva em conta as relações desses discursos e práticas com importantes momentos dramáticos da série, além de extensões transmídia e conteúdos (oficiais e de fãs) que circularam pelas redes durante a exibição da temporada,
9. BACCEGA, Maria Aparecida; TONDATO, Marcia Perencin. Fãs de telenovelas: construindo memórias - das mídias tradicionais às digitais. In: LOPES, Maria Immacolata Vassallo de (org.). Por uma teoria de fãs da ficção televisiva brasileira. Coleção Teledramaturgia, v. 4. Porto Alegre: Sulina, 2015, p. 65.

10. JENKINS, Henry. Cultura da convergência. São Paulo: Aleph, 2008, p. 39. 
11. Do termo inglês relationship. Consiste em aglutinar nomes de dois personagens, criando-se uma hashtag.

12. LOPES, Maria Immacolata Vassallo de. Telenovela como recurso comunicativo. MATRIZes, ano 3, n. 1, ago./dez. 2009 , p. 26-28.

13. JACKS, Nilda; PIENIZ, Mônica. Telenovelas em redes sociais: enfoque longitudinal na recepção de três narrativas. In: LOPES, Maria Immacolata Vassallo de (org.). Por uma teoria de fãs da ficção televisiva brasileira. Coleção Teledramaturgia, v. 4. Porto Alegre: Sulina, 2015, p. 312. com destaque para blogs, sites e plataformas sociais como Facebook, Twitter e Instagram.

A novela Em Família (Globo, 2014), de Manoel Carlos, foi objeto de investigação do grupo Obitel Brasil/UFSM, liderado por Veneza Ronsini e Liliane Brignol. O capítulo "Ativismo de fãs e disputas de sentidos de gênero nas interações da audiência de Em Família nas redes sociais" aponta que estratégias como shipping ${ }^{11}$, mutirão de postagens, memes e fanvideos, todas relacionadas ao romance das personagens Clara e Marina, ampliaram espaços de discussão social a respeito da homoafetividade. A cultura participativa se alia, portanto, às novas modalidades dos usos sociais e culturais da mídia e a produções de sentidos referentes a temas como orientação sexual e relações de gênero; a telenovela, por sua vez, mesmo com índices de audiência não tão expressivos como outrora, ainda se mostra como um dos mais importantes e amplos espaços de problematização do Brasil - e é justamente "na trajetória de personagens femininas, assim como na das representações do amor e da sexualidade, que se expressa de maneira mais bem acabada essa capacidade de aglutinar experiências públicas e privadas"12 tão cara ao formato.

O capítulo realizado pela equipe Obitel Brasil/UFRJ investiga o fenômeno da produção de memes nas redes sociais. "O riso e a paródia na ficção televisiva transmídia: os vilões em memes da internet”, trabalho orientado por Ana Paula Goulart Ribeiro e Igor Sacramento, parte de reflexões concernentes às reconfigurações do papel dos fãs na cultura da trasmidiação para analisar memes com vilões das telenovelas Salve Jorge (2012/2013), Amor à Vida (2013/2014) e Império (2014/2015), todas da TV Globo. A circulação de memes de personagens de telenovelas, constata-se, é uma atividade simbólica que legitima as ficções televisivas ao mesmo tempo em que altera conteúdos e contextos de forma criativa em muitos aspectos, tais como a paródia e o remix.

O capítulo "Telenovelas em redes sociais: enfoque longitudinal na recepção de três narrativas" finaliza a segunda parte do livro. A pesquisa do Obitel Brasil/UFRGS, coordenada por Nilda Jacks e Mônica Pieniz, acompanhou aspectos da nova relação da audiência com a telenovela das nove da Rede Globo a partir de três ficções distintas: Passione (2010/2011), Avenida Brasil (2012) e Império (2014/2015). Apesar de a primeira ter apresentado, por parte da esfera produtora, estratégias mais consistentes de extensão da narrativa em múltiplas plataformas, é na segunda que reside um ponto-chave no que se refere à intensificação de trocas entre produtores e receptores: a grande repercussão de Avenida Brasil motivou a emissora a investir na circulação da telenovela pelos ambientes digitais - prova disso é a incorporação de conteúdos criados pelos usuários nas táticas de divulgação da trama, considerada uma "fábrica de memes"13. Verifica-se, ainda, o fortalecimento das práticas de shippagem, incipientes dentre os fãs de Avenida Brasil e fartamente exploradas no decorrer da exibição de Império.

A terceira e última parte do livro abarca questões tangentes à cultura participativa, iniciando-se com trabalho do Obitel Brasil/UFPE, coordenado 
por Yvana Fechine. Intitulada "Governo da participação: uma discussão sobre processos interacionais em ações transmídias a partir da teledramaturgia da Globo", a pesquisa compreende o fenômeno da transmidiação subjugado à lógica de um dispositivo midiático de participação - que envolve mecanismos de permissão e interdição, de "gerenciamento" e "governo" das colaborações e das intervenções do público, a partir das estratégias acionadas pela instância produtora. Sob esse prisma, ao observar as ações transmídias desenvolvidas a partir de telenovelas exibidas pela TV Globo em 2015, o texto identifica quatro regimes interacionais: articulação, atuação, apropriação e desvio. Estes estão envolvidos em um processo dinâmico no qual se influenciam e se delimitam reciprocamente, atuantes em um jogo interdiscursivo de equilíbrio estável — como mostra a figura abaixo.

Figura 1. Relação entre regimes de interação

e modos de enunciação transmídia

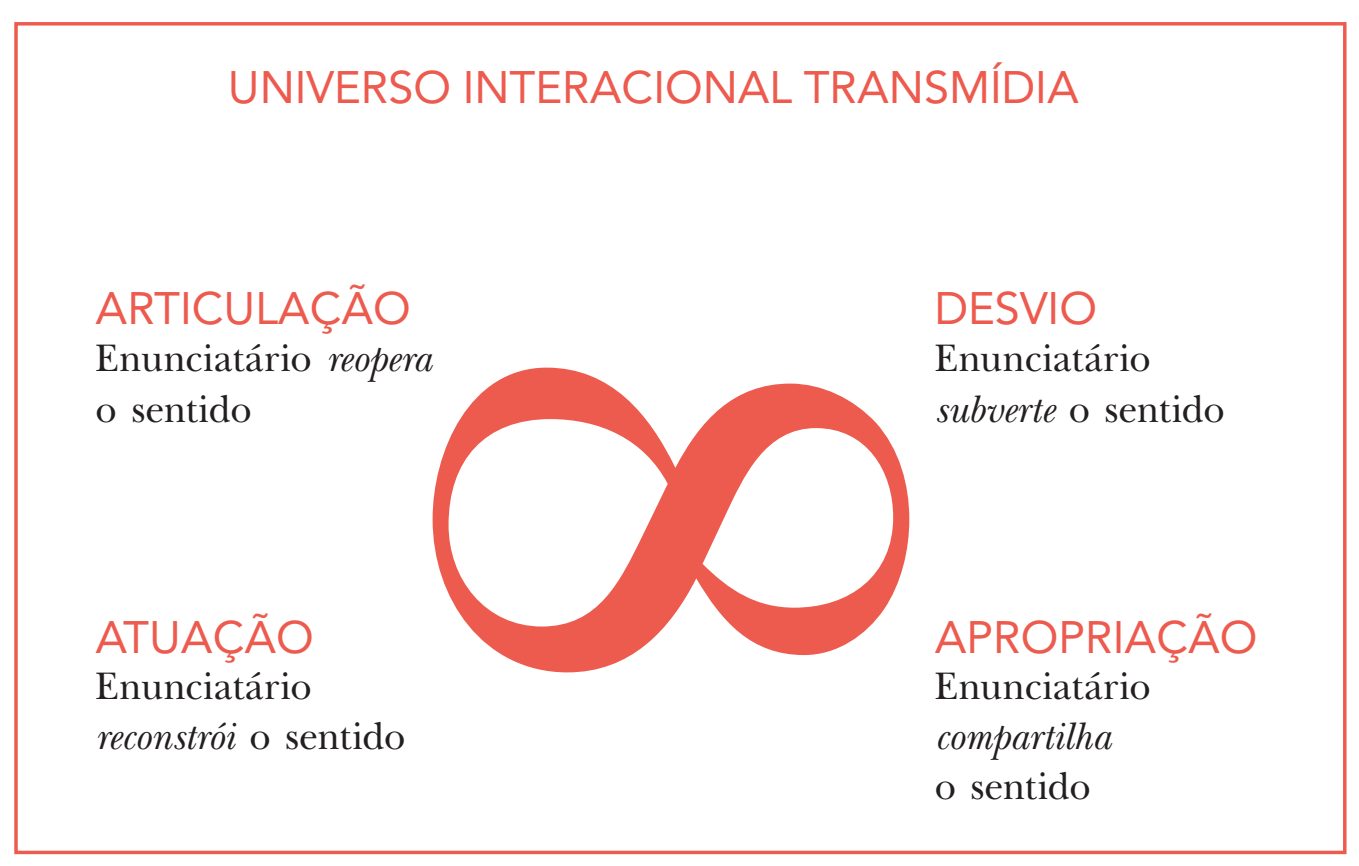

Fonte: Fechine et. $\mathrm{al}^{14}$

O Obitel Brasil/UAM, liderado por Renato Luiz Pucci Jr. e Vicente Gosciola, questionou-se acerca da existência de uma cultura participativa referente ao universo das séries brasileiras; seu foco, porém, ao contrário da equipe Obitel Brasil/UFSCar, residiu na TV aberta. "Televisão brasileira frente à problemática da cultura participativa: os casos de A Teia e O Rebu", segundo capítulo da terceira parte do livro, realiza uma análise comparativa de personagens,
14. FECHINE, Yvana. Governo da participação: uma discussão sobre processos interacionais em ações transmídias a partir da teledramaturgia da Globo. In: LOPES, Maria Immacolata Vassallo de (org.). Por uma teoria de fãs da ficção televisiva brasileira. Coleção Teledramaturgia, v. 4. Porto Alegre: Sulina, 2015, p. 352. 
15. PUCCl JR., Renato Luiz; GOSCIOLA, Vicente. Televisão brasileira frente à problemática da cultura participativa: os casos de A Teia e O Rebu. In: LOPES, Maria Immacolata Vassallo de (org.). Por uma teoria de fãs da ficção televisiva brasileira. Coleção Teledramaturgia, v. 4. Porto Alegre: Sulina, 2015 , p. 393

16. PIENIZ, Mônica. Tecnicidade como mediação empírica: a reconfiguração da recepção de telenovela a partir do Twitter. Tese de doutorado. Faculdade de Biblioteconomia e Comunicação, Universidade Federal do Rio Grande do Sul, Porto Alegre, 2013.

17. MOREIRA, Diego Gouveia. Cultura participativa na TV Globo: governo da audiência a partir de dispositivos midiáticos de participação. Tese de doutorado. Centro de Artes e Comunicação, Universidade Federal de Pernambuco, Recife, 2015.

18. CERQUEIRA, Renata Cristina Bento. Transmidiação na Rede Globo: análise das estratégias de conteúdo nos sites das telenovelas. Dissertação de mestrado. Faculdade de Comunicação, Universidade Federal da Bahia, Salvador, 2014

19. Doutoranda pelo Programa de Pós-Graduação em Comunicação da Universidade Federal de Pernambuco. Título do projeto: TV social: limites e transbordamentos entre a cultura participativa e a estratégia transmídia. Início: 2014. Orientadora: Yvana Fechine. narrativas e estilísticas das duas produções da Rede Globo exibidas em 2014, acompanhando a repercussão de ambas nas redes sociais e no portal Gshow. Dessa forma, contrapõem-se as séries a formatos pelos quais os brasileiros apresentam maior inclinação à participação, como a telenovela. Em ambos os casos, no entanto, constatou-se que as possibilidades de transmidiação exploradas pela emissora se restringiam aos níveis mais básicos da cultura participativa; a "perfurabilidade" 15 , isto é, o potencial para que os espectadores se aprofundem em questões suscitadas pelas ficções, fundamentava-se somente nas complexidades e ambiguidades das narrativas.

O último capítulo, desenvolvido pela equipe Obitel Brasil/UFJF — coordenada por Maria Cristina Brandão de Faria e Gabriela Borges —, também tem como objeto a telenovela $O$ Rebu, traçando uma cartografia tanto dos mecanismos de produção e das estratégias de transmidiação propostas pela TV Globo quanto da lógica do consumo, analisada sob a óptica do recente fenômeno da Social TV. "Cultura participativa na esfera ficcional de O Rebu" aponta o remake como uma reconfiguração da obra original de Bráulio Pedroso, exibida em 1974, para estes tempos de tecnologias digitais, capaz de atrair tanto aqueles que tiveram um vínculo afetivo com a trama original quanto os curiosos que apenas "ouviram falar" da produção; essa perspectiva se fez palpável na multiplicidade de fenômenos transmidiáticos - gerada principalmente no âmbito da recepção - relacionadas à trama. Ao comentar os acontecimentos de $O$ Rebu nas redes sociais, o público produziu novos significados e, consequentemente, expandiu o universo ficcional da telenovela — processo também tangenciado pela equipe Obitel Brasil/UFRJ, recorda-se.

Ao analisarem o remake de $O$ Rebu no cenário da cultura participativa, Faria e Borges retomam conceitos postulados por Fechine nos dois volumes anteriores da Coleção Teledramaturgia. Fechine, por sua vez, conflui temas e discussões caros a toda a sua trajetória acadêmica — como a noção de dispositivo — aos trabalhos do grupo Obitel Brasil/UFPE; ela e Jacks (Obitel Brasil/UFRGS) orientam suas respectivas equipes numa espécie de continuum, aprofundando questões já esboçadas em pesquisas anteriores. Destaca-se, ainda, a convergência de algumas equipes com importantes grupos de pesquisa voltados aos estudos do audiovisual, tais como CETVN (Centro de Estudos de Telenovela), da ECA-USP; GEMInIS (Grupo de Estudos sobre Mídias Interativas em Imagem e Som), da UFSCar; A-Tevê — Laboratório de Análise de Teleficção, da UFBA; e Inovações e Rupturas na Ficção Televisiva Brasileira, da UAM.

Dessa forma, a Rede Brasileira de Pesquisadores de Ficção Televisa Obitel Brasil se fortalece consoante ao seu principal objeto - o cenário de transmidiação no qual a teleficção atualmente está inserida: as pesquisas e as próprias equipes se retroalimentam, tanto no que tange à afinidade temática quanto às práticas e procedimentos de investigação. Sob esses dois sentidos, a rede caminha num profícuo diálogo com a atual episteme do campo da Comunicação.

Além disso, são notórias as influências das pesquisas do Obitel Brasil nos trabalhos dos demais integrantes das equipes. As teses de Mônica Pieniz ${ }^{16}$ (Obitel 
Brasil/UFRGS), Diego Gouveia ${ }^{17}$ (Obitel Brasil/UFPE) e a dissertação de Renata Cerqueira $^{18}$ (Obitel Brasil/UFBA), bem como o doutorado em andamento de Cecília Almeida ${ }^{19}$ (Obitel Brasil/UFPE) e as pesquisas das mestrandas Gêsa Cavalcanti $^{20}$ (Obitel Brasil/UFPE) e Daiana Sigiliano ${ }^{21}$ (Obitel Brasil/UFJF), abordam, sob diversas perspectivas teórico-metodológicas, questões referentes aos fenômenos da transmidiação, cultura participativa e Social TV; constituem, portanto, prova irrefutável do fôlego e da consolidação da rede.

As teses de Claudia Freire ${ }^{22}$ e Clarice $\mathrm{Greco}^{23}$, ambas integrantes do grupo Obitel Brasil/USP, endossam o enunciado do título da publicação aqui resenhada: é necessária uma pesquisa nacional voltada à prática dos fãs, capaz de "antropofagizar" - no melhor sentido oswaldiano — os estudos estrangeiros ao relacioná-los com o contexto brasileiro, no qual a telenovela (e a própria televisão), mesmo em meio a um cenário dinâmico de convergência e transmidiação, ainda ocupa um espaço central. Percebe-se, mais do que nunca, a operação de uma "modernidade não contemporânea" ${ }^{4}$ em nosso país, na qual coexistem "o tradicional e o moderno, culturas étnicas e novas tecnologias, formas de produção artesanal e industrial” ${ }^{25}$.

Por uma teoria de fãs da ficção televisiva brasileira lança diversos focos de luz em questões que, provavelmente, serão desdobradas nas próximas pesquisas da rede Obitel Brasil, visando à consolidação de técnicas e métodos concernentes à cultura fandom que melhor dialoguem com a realidade brasileira. Primeiro passo nesse sentido, é, contudo, mais um avanço na caminhada de uma rede de pesquisa profícua e visionária. Ao colocar o fã da ficção televisiva como centro de suas pesquisas, o Obitel Brasil nada mais busca que uma maior "compreensão da natureza do vínculo social frente à sociabilidade orquestrada pela mídia”"26, percepção importante no difuso atual cenário da Comunicação.

Em uma das reuniões do CETVN à qual estive presente, Maria Immacolata Vassallo de Lopes, ao tratar da preponderância das imagens no mundo contemporâneo, rememorou a questão do mito da caverna, pelo qual Platão colocava as imagens como um engano. Para uma sociedade como a ocidental, calcada na razão e na escrita, não é à toa o terror por parte do próprio homem ao encarar um mundo no qual a articulação da tecnologia eletrônica com a vida humana o expõe continuamente a imagens e mais imagens. Nesse decurso, "a Comunicação está no olho do furacão" - palavras textuais de Lopes.

Para onde vão todas essas imagens? Para nuvens? O quanto as pessoas, as ideias, os comportamentos, os movimentos, as interações e a formação das subjetividades são afetados pelo ir e vir de imagens, por todas essas mudanças? O que tudo isso significa, afinal, para o receptor? Todas essas questões, problematizadas por Lopes naquela reunião, reverberam na investigação dos fãs da ficção televisiva brasileira em meio ao cenário transmidiático. Afinal, este fã nada mais é do que um retrato do homem contemporâneo - um homem que está em múltiplas telas.
16. PIENIZ, Mônica. Tecnicidade como mediação empírica: A reconfiguração da recepção de telenovela a partir do Twitter. Tese de doutorado. Faculdade de Biblioteconomia e Comunicação, Universidade Federal do Rio Grande do Sul, Porto Alegre, 2013.

17. MOREIRA, Diego Gouveia. Cultura participativa na TV Globo: Governo da audiência a partir de dispositivos midiáticos de participação. Tese de doutorado. Centro de Artes e Comunicação, Universidade Federal de Pernambuco, Recife, 2015.

18. CERQUEIRA, Renata Cristina Bento. Transmidiação na Rede Globo: Análise das estratégias de conteúdo nos sites das telenovelas. Dissertação de mestrado. Faculdade de Comunicação, Universidade Federal da Bahia, Salvador, 2014.

19. Doutoranda pelo Programa de Pós-Graduação em Comunicação da Universidade Federal de Pernambuco. Título do projeto: TV social: Limites e transbordamentos entre a cultura participativa e a estratégia transmídia. Início: 2014. Orientadora: Yvana Fechine.

20. Mestranda pelo Programa de Pós-Graduação em Comunicação da Universidade Federal de Pernambuco. Título do projeto: Telenovela, Social TV e segunda tela: Processo de virtualização do assistir. Início: 2014. Orientadora: Yvana Fechine.

21. Mestranda pelo Programa de Pós-Graduação em Comunicação da Universidade Federal de Juiz de Fora. Título do projeto: Social TV: Novos paradigmas de engajamento e participação. Início: 2015. Orientadora: Gabriela Borges. 
22. FREIRE, Claudia. Método de monitoramento de redes sociais: Epistemologia, técnicas e propostas de mineração de bancos de dados para conteúdos gerados por fãs de telenovela em redes sociais. Tese (Doutorado em Ciências da Comunicação) - Escola de Comunicações e Artes, Universidade de São Paulo. São Paulo, 2015.

23. GRECO, Clarice. TV Cult no Brasil: Memória e culto às ficções televisivas em tempos de mídias digitais. Tese (Doutorado em Ciências da Comunicação) - Escola de Comunicações e Artes, Universidade de São Paulo. São Paulo, 2016.

24. MARTÍN-BARBERO, Jesús. Dos meios às mediações: Comunicação, cultura e hegemonia. Rio de Janeiro: Editora UFRJ, 2008, p. 214.

25. GARCÍA CANCLINI, Néstor. Culturas híbridas: Estratégias para entrar e sair da modernidade. São Paulo: Edusp, 1997, p. 19.

26. SODRÉ, Muniz. A ciência do comum: Notas para o método comunicacional. Petrópolis: Vozes, 2014, p. 187.

\section{REFERÊNCIAS}

GARCÍA CANCLINI, Néstor. Culturas híbridas: Estratégias para entrar e sair da modernidade. São Paulo: Edusp, 1997.

JENKINS, Henry. Cultura da convergência. São Paulo: Aleph, 2008.

LOPES, Maria Immacolata Vassallo de (org.). Ficção televisiva no Brasil: Temas e perspectivas. Coleção Teledramaturgia, v. 1. São Paulo: Globo, 2009.

Ficção televisiva transmidiática no Brasil: Plataformas, convergência, comunidades virtuais. Coleção Teledramaturgia, v. 2. Porto Alegre: Sulina, 2011.

Estratégias de transmidiação na ficção televisiva brasileira. Coleção Teledramaturgia, v. 3. Porto Alegre: Sulina, 2013.

Por uma teoria de fãs da ficção televisiva brasileira. Coleção Teledramaturgia, vol. 4. Porto Alegre: Sulina, 2015.

Telenovela como recurso comunicativo. MATRIZes, ano 3, n. 1, ago./ dez. 2009.

MARTÍN-BARBERO, Jesús. Dos meios às mediações: Comunicação, cultura e hegemonia. Rio de Janeiro: Editora UFRJ, 2008.

SODRÉ, Muniz. A ciência do comum: Notas para o método comunicacional. Petrópolis: Vozes, 2014. 